\title{
Qualidade microbiológica de salada de frutas comercializadas por ambulantes na cidade de Juazeiro do Norte - Ceará
}

\section{Microbiological quality of fruit salad sold by street vendors in the city of Juazeiro do Norte - Ceará}

\author{
Jôcy Emanuela Ferreira dos Santos ${ }^{1}$, Lúcia Emanuele Barros Teixeira I*, Inácia dos Santos Moreira ${ }^{2}$, Francinalva Cordeiro \\ de Sousa ${ }^{2}$, Deise Souza de Castro ${ }^{3}$
}

RESUMO: O presente trabalho avaliou a qualidade microbiológica de salada de frutas comercializadas por ambulantes na cidade de Juazeiro do Norte - Ceará. Foram coletadas seis amostras de salada de frutas, sendo duas em cada ponto de coleta. As amostras foram coletadas pela manhã no centro da cidade, as amostras foram mantidas em recipientes isotérmicos e levadas para o Laboratório de Microbiologia de Alimentos da FATEC - Cariri. Realizaram-se análises de coliformes a $45^{\circ} \mathrm{C}$ e Salmonella spp, segundo as Normas da APHA 2001. Os resultados foram interpretados de acordo com a RDC $\mathrm{N}^{\circ} 12$, de janeiro de 2001 da ANVISA. Para coliformes a $45^{\circ} \mathrm{C}$ foram encontrados resultados iguais a $2,4 \times 10^{2} \mathrm{NMP} / \mathrm{g} ; 1,5 \times 10^{2} \mathrm{NMP} / \mathrm{g} ; 4,6 \times 10^{2}$ $\mathrm{NMP} / \mathrm{g} ; \geq 2,4 \times 10^{2} \mathrm{NMP} / \mathrm{g} ; 4,6 \times 10^{2} \mathrm{NMP} / \mathrm{g}$ e $\geq 2,4 \times 10^{2}$, para as amostras $\mathrm{A}_{1}, \mathrm{~A}_{2}, \mathrm{~B}_{1}, \mathrm{~B}_{2}, \mathrm{C}_{1}$ e $\mathrm{C}_{2}$ respectivamente. Estes resultados revelam que $33,33 \%$ das amostras, encontra-se em desacordo com o padrão federal vigente que permite $5 \times 10^{2}$ NMP/g. Para Salmonella spp., os resultados encontrados foram de ausência em todas as amostras.

Palavras-chave: Fruto, Investigação, Microrganismos.

\begin{abstract}
This study evaluated the microbiological quality of fruit salad sold by street vendors in the city of Juazeiro do Norte - Ceará. Six samples were collected fruit salad, two in each collection point. Samples were collected in the morning in the city center, the samples were kept in insulated containers and taken to the Laboratory of Food Microbiology FATEC Cariri. Analyses were performed for coliforms at $45^{\circ} \mathrm{C}$ and Salmonella spp, under the Rules of 2001 APHA The results were interpreted according to RDC No. 12, January 2001 ANVISA. For coliforms at $45^{\circ} \mathrm{C}$ similar results were found 2,4x102

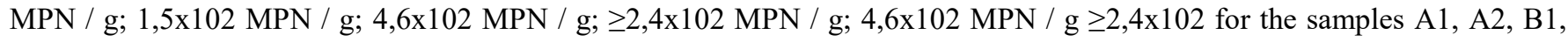
$\mathrm{B} 2, \mathrm{C} 1$ and $\mathrm{C} 2$ respectively. These results show that $33.33 \%$ of the samples is in disagreement with the current Federal Standard which allows 5x102 NMP / g. For Salmonella spp., The results were absent in all samples.
\end{abstract}

Keywords: Fruit, Research, Microorganisms.

\footnotetext{
*Autor para correspondência

Recebido em 08/11/2014 e aceito em 14/20/2015

${ }^{1}$ Tecnólogos (as) em Alimentos pela Faculdade de Tecnologia CENTEC / FATAC - Cariri, Rua Amália Xavier S/N, Bairro Triangulo. Cep: 63000-000. Juazeiro do Norte-CE. E-mail:emanubarros@hotmail.com;

${ }^{2}$ Doutorandas do Programa de Pós-Graduação em Engenharia Agrícola, Universidade Federal de Campina Grande - UFCG ,Campina Grande - PB, Brasil.Emails:francis_nalva@yahoo.com.br; inaciamoreira@ymail.com;

${ }^{1}$ Mestranda do Departamento de Engenharia Agrícola, Área de Armazenamento e Processamento de Produtos Agrícolas, UAEAg/CTRN/UFCG - Campina Grande-PB, Brasil. E-mail: deise_castro01@hotmail.com
} 


\section{INTRODUÇÃO}

O comércio ambulante de alimentos torna-se uma fonte de renda para várias famílias devido à falta de emprego e/ou qualificação profissional e ao mesmo tempo, surge como uma alternativa para pessoas que precisam se alimentar de forma rápida e prática, por não possuírem muito tempo, devido as diversas atividades realizadas. Estes alimentos muitas vezes são expostos em vias públicas, sujeitos contaminação e a poluição.

As frutas por serem perecíveis, sofrem deterioração em poucos dias, dificultando sua comercialização. A salada de frutas surge como uma alternativa para o aproveitamento de frutas durante a safra. As frutas possuem vários nutrientes, como vitaminas e minerais que ajudam na manutenção do corpo e as fibras que ajudam a digestão, mantendo um sistema digestivo saudável.

A vida corrida da população em geral faz com que os consumidores procurem maior facilidade e qualidade na área alimentícia. Por isso, vem crescendo no mercado a procura por alimentos minimamente processados. Este método de processamento foi introduzido no Brasil na década de 1990 e emprega operações que eliminam suas partes não comumente consumidas como cascas, talos e sementes (SMANIOTO et al., 2009). Devido à elevada manipulação e ao incremento no consumo de minimamente processados, tanto em âmbito doméstico quanto institucional, a preocupação com o risco potencial para a saúde pública aumentou, devido à probabilidade de contaminação microbiológica (SANTOS et al., 2010).

Segundo Franco e Landgraf (2005), a salada de frutas é considerada um bom substrato para a proliferação de microrganismos devido ao seu teor de água que favorece o crescimento de leveduras e bactérias; $\mathrm{pH}$ ácido, favorecendo o crescimento de bolores e leveduras; a alta manipulação durante o preparo podendo levar a contaminação por microrganismos indicadores; além de condições inadequadas de temperatura durante o armazenamento.

Um alimento seguro é aquele que apresenta índices de contaminação físicos, químicos e biológicos seguros para o consumo, de forma que não acarrete danos à saúde do consumidor. As doenças transmitidas pelo consumo de alimentos contaminados constituem tanto um destacável problema de saúde pública quanto um risco importante para as empresas do setor alimentício (FERRARI et al., 2013). De acordo com SANTOS et al (2010), as frutas e verduras são fontes potenciais de microrganismos patogênicos, sendo frequentemente incriminadas em doenças de origem alimentar (DTAs) em várias partes do mundo.

Diante do exposto o presente trabalho teve como objetivo avaliar a qualidade microbiológica de salada de frutas, comercializadas por ambulantes no centro da cidade de Juazeiro do Norte - Ceará.

\section{MATERIAL E MÉTODOS}

\section{Coleta e preparação das amostras}

Este estudo foi realizado durante os meses de junho e julho de 2011, no qual foram utilizadas seis amostras de salada de frutas, em copos descartáveis de $250 \mathrm{ml}$, adquiridas diretamente dos ambulantes as mesmas foram coletadas cuidadosamente pela manhã, em três pontos de comercialização na cidade de Juazeiro do Norte-CE, em cada ponto foram coletadas duas amostras as quais foram acondicionadas em recipientes esterilizados em autoclave e em seguida foram acomodadas em caixas isotérmicas e transportadas para o Laboratório de Microbiologia de Alimentos da Faculdade de Tecnologia CENTEC / FATEC Cariri. As análises foram realizadas em três repetições, para obtenção de resultados mais confiáveis, cada repetição foi coletada em semanas diferentes.

\section{Analises laboratoriais}

As análise realizadas foram de coliformes a $45^{\circ} \mathrm{C}$ e Salmonella spp, segundo as Normas da American Public Health Association (APHA), 2001. A interpretação dos resultados foi feita de acordo com os critérios microbiológicos estabelecidos na legislação brasileira, regida pela RDC $\mathrm{N}^{\circ} 12,02$ de janeiro de 2001 da Agência Nacional de Vigilância Sanitária - ANVISA.

\section{Análises Microbiológicas}

Os coliformes totais e fecais foram determinados pela técnica de fermentação em tubos múltiplo, utilizando para o teste presuntivo o caldo lactosado simples e no teste confirmativo caldo lactose bile verde brilhante, ambos com incubação a $35^{\circ} \mathrm{C}$ por 48 horas. Considerou-se como positivo, os tubos que apresentassem gás no tubo de Durhan. Os coliformes fecais foram determinados por inoculação dos tubos com gás positivos em caldo Escherichia coli com incubação a $45{ }^{\circ} \mathrm{C}$ por 24 horas.

Pesquisa de Salmonella spp. realizada após a pesagem da amostra em caldo lactose, incuba-se a $35-37{ }^{\circ} \mathrm{C}$ durante 24 horas. Transcorrido o tempo de incubação a amostra é colocada em tubos que contenham o caldo tetrationato, caldo selenito-cistina e caldo RappaportVassiliadis e incubadas a $42-43^{\circ} \mathrm{C} / 24 \mathrm{~h}$. Após o período de incubação, realiza-se o plaqueamento diferencial fazendo estrias com alça de níquel nos meios seletivos: Brilliant Green Agar, Xilose Lisina, Hektoen Enteric Agar e SalmonellaShigella Agar, incuba a $35-37{ }^{\circ} \mathrm{C}$ por 24 horas. Transcorrido o período de incubação do plaqueamento diferencial, faz-se a prova bioquímica, transferindo as colônias com o auxílio de agulha de platina e inoculação por picada e estrias nos tubos inclinados com os seguintes meios: Agar Lisina Ferro e Agar Tríplice Açúcar Ferro. Incubar a $35-37{ }^{\circ} \mathrm{C}$ por 24 horas e observar se há a ocorrência de reação típica de Salmonella.

\section{RESULTADOS E DISCUSSÃO}

Os resultados obtidos nas análises microbiológicas das amostras de salada de frutas estão expressos na Tabela 1. Verificasse que $33,33 \%$ das amostras encontram-se contaminadas por coliformes a $45^{\circ} \mathrm{C}$, estando em desacordo com o padrão federal vigente que permite $5 \times 10^{2} \mathrm{NMP} / \mathrm{g}$. A contaminação por coliformes indica que houve contaminação antes, durante ou após o preparo das saladas, necessitando de uma maior atenção dos manipuladores quanto à higiene, para evitar a proliferação destes microrganismos, pois uma vez contaminado o alimento poderá causar risco a saúde do consumidor. 


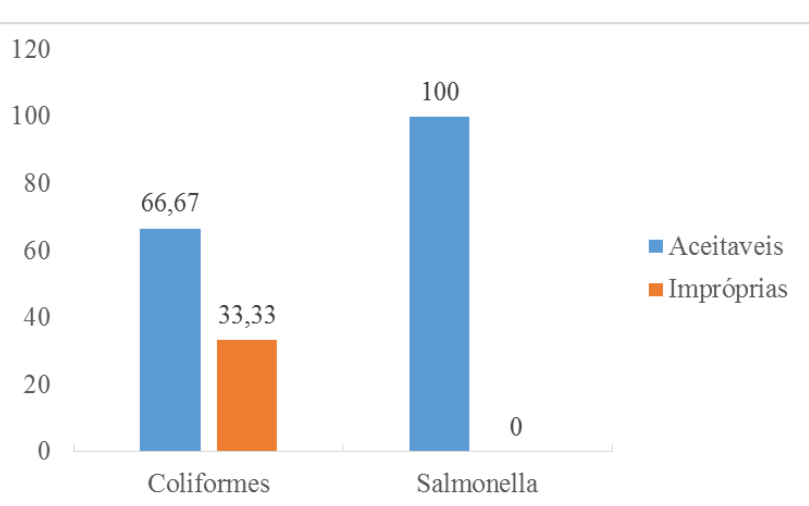

Figura 1. Distribuição da contagem de coliformes a $45{ }^{\circ} \mathrm{C}$ $\mathrm{NMP} / \mathrm{mL}$ e Salmonella sp. em amostras de saladas de frutas comercializadas por ambulantes na cidade de Juazeiro do Norte - CE.

Pinheiro et al. (2011) ao avaliarem a qualidade microbiológica de salada de frutas tropicais verificaram que todas as amostras (21amostras) de saladas de frutas encontram-se dentro dos padrões legais vigentes para coliformes termotolerante.

Análises de coliformes e Salmonella realizados em salada de frutas em calda (SOUZA \& CÓL, 2014) confirmaram um produto com boa embalagem, sem vazamento, estufamento ou fermentação, isento de microrganismos deteriorantes e Patogênicos, dentro dos padrões de segurança higiênico-sanitários estipulados pela legislação.

Palu et al. (2002) ao analisarem 15 amostras de frutas prontas para o consumo, encontraram 13,33\% (duas) das amostras estavam contaminadas com coliformes termotolerantes, sendo uma de mamão $\left(2,4 \times 10^{4} \mathrm{NMP} / \mathrm{g}\right)$ e outra de melão $\left(3,5 \times 10^{3} \mathrm{NMP} / \mathrm{g}\right)$. Pinheiro et al. (2005) em seu estudo sobre avaliação da qualidade microbiológica de frutos minimamente processado, das 100 amostras analisadas identificaram em $28(28 \%)$ das amostras a presença de coliformes termotolerantes com valores superiores ao padrão estabelecido pela legislação, ou seja, superior a $5 \times 10^{2} \mathrm{NMP} / \mathrm{g}$.

Pinheiro et al (2005) relatam que a presença de coliformes termotolerantes indica que os frutos minimamente processados tiveram contato direto e/ou indireto com fezes, uma vez que a Escherichia coli não faz parte da microflora normal dos produtos frescos, por apresentar habitat exclusivo no intestino do homem e animais de sangue quente. Além de indicar a possível presença de enteropatógenos, várias cepas de E. coli são patogênicas ao homem.

Para Salmonella spp., os resultados encontrados foram de ausência em todas as amostras. Sendo, portanto, considerado "produto em condições sanitárias insatisfatórias" para o consumo. Pinheiro et al. (2011) também encontraram ausência de Salmonella spp em amostras de salada de frutas. Já outros autores como Pinheiro et al. (2005) avaliando a qualidade microbiológica de frutos minimamente processado, constataram que 25 (25\%), estavam contaminadas com Salmonella sp

\section{CONCLUSÃO}

Os resultados obtidos mostraram que $33,33 \%$ das saladas de frutas analisadas se encontram fora dos padrões estabelecidos pela legislação vigente com relação a coliformes $45^{\circ} \mathrm{C}$. Esses resultados sugerem uma falta de controle sanitário, evidenciando que a escolha de matériasprimas, as condições higiênicas durante e após o processamento e condições de armazenamento não estão de acordo com as boas práticas de fabricação (BPF).

\section{REFERÊNCIAS BIBLIOGRÁFICAS}

AMERICAN PUBLIC HEALTH ASSOCIATION. Compendium of methods for the microbiological examination of foods. 4.ed. Washington, DC, 1992. methods.

BRASIL. Regulamento técnico sobre padrões microbiológicos para alimentos RDC $\mathrm{N}^{\circ} 12,02 \mathrm{de}$ janeiro de 2001. ANVISA, 2001.

FRANCO, B.D.G.M; LANDGRAF, M. Microbiologia dos Alimentos. Atheneu. São Paulo: 2005.

OLIVEIRA, A. M.; GONÇALVES, M. O.; SHINOHARA, N. K. S.; STAMFORD, T. L. M. Manipuladores de alimentos: um fator de risco. Revista Higiene Alimentar, v. 17, n. 114/115, p. 12-17, 2003.

PALÚ, A. P, TIBANA, A.; TEIXEIRA, L. M.; MIGUEL, M. A. L.; PYRRHO, A. S.; LOPES, H. R. Avaliação microbiológica de frutas e hortaliças frescas, servidas em restaurantes self-sevrice privados, da Universidade Federal do Rio de Janeiro. Revista Higiene Alimentar, São Paulo, v.16, n.100, p.67-74, 2002.

PINHEIRO, A. M.; ABREU, C. R. A.; MAIA, G. A.; SOUSA, P. H. M.; FIGUEIREDO, E. A. T.; ROCHA, E. M. F. F.; COSTA, J. M. C. Avaliação das características de qualidade, componentes bioativos e qualidade microbiológica de salada de frutas tropicais. Alimentos e Nutrição, Araraquara, v. 22, n.3, p. 435-440, 2011.

PINHEIRO, N. M. S. et al. Avaliação da qualidade microbiológica de frutos minimamente processados comercializados em supermercados de Fortaleza. Revista Brasileira de Fruticultura, Jaboticabal - SP, v. 27, n. 1, p. 153-156, 2005.

SANTOS, T. B. A.; SILVA, N.; JUNQUEIRA, V. C. A.; PEREIRA, J. L. Microrganismos indicadores em frutas e hortaliças minimamente processadas. Brazilian Journal Food Technology, v.13, n.2, p.141-146, 2010.

FERREARI, C. K. B.; ASSUMPÇÃO, C. F.; MORZELLE, M. C.; FERRARI, G. S. L.; SOUZA, E. C. Avaliação microbiológica em alimentos de cantinas escolares na região do médio Araguaia (MT/GO). Revista Baiana de Saúde Pública, v.37, n.1, p.45-56, 2013.

SMANIOTO, F.; PIROLO, N. J.; SIMIONATO, E. M. R. S.; ARRUDA, M. C. Qualidade microbiológica de frutas e hortaliças minimamente processadas. Revista Instituto Adolfo Lutz, v.68, n.1, p.50-54, 2009.

SOUZA, F. G.; CÓL, C. D. Elaboração, qualidade físicoquímica, microbiológica e sensorial da salada de frutas em calda. Revista Brasileira de Produtos Agroindustriais, v.16, n.3, p.313-317, 2014. 